\title{
The influence of combined oral contraceptives containing drospirenone on hypothalamic-pituitary-adrenocortical axis activity and glucocorticoid receptor expression and function in women with polycystic ovary syndrome
}

\author{
Djuro Macut, ${ }^{1}$ Ivana Božić Antić, Jelena Nestorov, ${ }^{2}$ Vladanka Topalović, ${ }^{2}$ \\ Jelica Bjekić Macut, ${ }^{3}$ Dimitrios Panidis, ${ }^{4}$ Biljana Kastratović Kotlica, ${ }^{5}$ \\ Efstathios Papadakis, ${ }^{4}$ Gordana Matić, ${ }^{2}$ Danijela Vojnović Milutinović ${ }^{2}$
}

\begin{abstract}
${ }^{1}$ Institute of Endocrinology, Diabetes and Metabolic Diseases, Clinical Center of Serbia and School of Medicine, University of Belgrade; 'Department of Biochemistry, Institute for Biological Research "Sinisa Stanković", University of Belgrade; ${ }^{3} \mathrm{CHC}$ Bežanijska kosa; Belgrade, Serbia; ${ }^{4}$ Division of Endocrinology and Human Reproduction, $2^{\text {nd }}$ Department of Obstetrics and Gynecology, Aristotle University of Thessaloniki, Thessaloniki, Greece; ${ }^{5} \mathrm{Clinic}$ of Obstetrics and Gynecology, Faculty of Medicine, University of Belgrade, Belgrade, Serbia
\end{abstract}

\begin{abstract}
OBJECTIVE: Most women with PCOS have increased adrenal androgen production, enhanced peripheral metabolism of cortisol and elevation in urinary excretion of its metabolites. Increased cortisol clearance in PCOS is followed by a compensatory overdrive of the hypothalamic-pituitary-adrenocortical (HPA) axis. We hypothesized that oral contraceptives containing ethinylestradiol and drospirenone (EE-DRSP) could modulate glucocorticoid receptor (GR) expression and function and thus affect HPA axis activity in PCOS patients. DESIGN: We analyzed 12 women with PCOS (age $24.17 \pm 4.88$ years; body mass index $22.05 \pm 3.97 \mathrm{~kg} / \mathrm{m}^{2}$ ) treated for 12 months with EE-DRSP and $20 \mathrm{BMI}-\mathrm{matched}$ controls. In all subjects testosterone, dehydroepiandrosterone sulfate (DHEAS), sex hormone-binding globulin (SHBG), cortisol (basal and after dexamethasone), concentrations of GR protein, phospo-GR211 protein, number of GR per cell $\left(B_{\max }\right)$ and its equilibrium dissociation constant $\left(K_{D}\right)$ were measured. RESULTS: Before treatment, increased concentrations of testosterone and DHEAS ( $<<0.001$, respectively), unaltered basal cortisol and an increased sensitivity $(p<0.05)$ of the HPA axis to dexamethasone were observed in PCOS women in comparison to controls. After treatment, testosterone $(p<0.01)$, DHEAS $(p<0.05)$ and cortisol suppression after dexamethasone $(p<0.01)$ were decreased in PCOS women. There were no changes in GR protein concentration, GR phosphorylation nor in the receptor functional parameters $B_{\max }$ and $K_{D}$ in women with PCOS before and after the therapy, and in comparison to controls. CONCLUSIONS: Prolonged treatment with EE-DRSP
\end{abstract}


in PCOS women decreased serum androgens and increased cortisol in the presence of decreased sensitivity of the HPA axis and did not exert changes in GR expression and function.

Key terms: Combined oral contraceptives, Cortisol, Drospirenone, Glucocorticoid receptor, HPA axis, Polycystic ovary syndrome

\section{INTRODUCTION}

Polycystic ovary syndrome (PCOS) is a common endocrinopathy that affects $6-8 \%$ of reproductiveaged women. ${ }^{1}$ It is a heterogeneous syndrome with a wide range of clinical characteristics and metabolic abnormalities. $^{2}$

The primary irregularity in women with PCOS is an abnormal androgen synthesis and secretion, particularly by ovarian theca cells, and to a lesser degree by adrenals. ${ }^{2,3}$ It seems that hyperinsulinemia and insulin resistance play a central role in the pathogenesis of PCOS, which predisposes these women to a risk of various metabolic abnormalities, including type 2 diabetes and cardiovascular diseases. ${ }^{4}$ Furthermore, hyperinsulinemia stimulates both ovarian and adrenal androgen secretion and suppresses sex hormone-binding globulin (SHBG) synthesis from the liver, leading to an increase in free, biologically active androgens. ${ }^{4}$

Besides an increase in adrenal androgen production, there is an enhanced peripheral metabolism of cortisol and elevation in urinary excretion of its metabolites in most women with PCOS. ${ }^{5,6}$ Increased cortisol clearance in PCOS is followed by a compensatory overdrive of the hypothalamic-pituitary-adrenocortical (HPA) axis. ${ }^{7}$ Regulation of the HPA axis by cortisol is mediated by the low affinity glucocorticoid receptor (GR) and the high affinity mineralocorticoid receptor (MR) in the brain. Elevations in circulating cortisol inhibit the HPA axis by acting via the GR in a direct and indirect fashion through the anterior pituitary, hypothalamus and hippocampus. ${ }^{8}$ Cellular actions of glucocorticoids are mediated by GR, which functions as a ligand-dependent transcription factor and undergoes conformational change, translocates into the nucleus and influences transcription of responsive genes. ${ }^{9}$ Cortisol action on target tissues depends on its circulating concentration and intracellular metabolism, as well as on the level GR expression, its hormone- binding activity, translocation to the nucleus, binding to DNA and transactivation/transrepression activity. ${ }^{10}$ The phosphorylation of the GR is an important posttranslational modification of the GR which modulates its transcriptional activity, alters its protein stability and subcellular location and results in enhanced or inhibited GR-induced gene expression. ${ }^{11}$ Phosphorylation status of the GR at serine-211 (pGR-Ser211) is considered to be a biomarker of GR function. ${ }^{12,13}$

Therapeutic approaches toward suppressing ovarian androgen production in PCOS are commonly performed using combined oral contraceptives (COCs), thus providing clinical improvement of hirsutism, menstrual regularity and weight control. ${ }^{14}$ One of the widely used COCs for the treatment of PCOS is a low dose estrogen-progestin combination containing ethinylestradiol (EE) and drospirenone (DRSP). While the EE component of COC inhibits folliculogenesis and enhances SHBG production followed by reduction in circulating levels of free testosterone and its bioavailability, DRSP has antiandrogenic and antimineralocorticoid properties with no estrogenic and glucocorticoid activity. ${ }^{14}$

In our previous study, we showed that PCOS is associated with increased sensitivity of the HPA axis to dexamethasone. This increase in sensitivity to dexamethasone was accompanied by an elevated lymphocytes GR protein concentration that was not followed by alterations in the receptor functional status. ${ }^{15}$ In the present study, we aimed to analyze the sensitivity of the HPA axis to dexamethasone in women with PCOS before and after 12 months of therapy with a COC containing an EE-DRSP combination. We hypothesized that alterations in phosphorylation of GR, and GR function, may underlie possible PCOS-related impairment of HPA axis activity that could be altered by COC treatment. To that end, we investigated the level of GR-Ser211 phosphorylation, as a biomarker of GR transcriptional activity, 
as well as GR functional parameters: equilibrium dissociation constant $\left(\mathrm{K}_{\mathrm{D}}\right)$, number of GR per cell $\left(\mathrm{B}_{\max }\right)$ and $\mathrm{K}_{\mathrm{D}} / \mathrm{B}_{\max }$ ratio at baseline and after the 12 months therapy with COC.

\section{SUBJECTS AND METHODS}

\section{Subjects}

A total of 32 women were investigated. Twelve women with PCOS [mean age \pm SD, $24.17 \pm 4.88$ years; mean body mass index (BMI), $22.05 \pm 3.97$ $\left.\mathrm{kg} / \mathrm{m}^{2}\right]$ and $20 \mathrm{BMI}-$ matched healthy controls (mean age, $29.10 \pm 3.90$ years; mean BMI, $23.50 \pm 2.25 \mathrm{~kg}$ / $\mathrm{m}^{2}$ ) participated in the study. All the participants were recruited during a 24-month period from the outpatient clinic where they were referred for oligo- or amenorrhea, hirsutism, acne or infertility. They gave written informed consent for participation in this study and the study was approved by the Ethical Committee of the School of Medicine, University of Belgrade.

The diagnosis of PCOS was made on the basis of the revised 2003 Rotterdam ESHRE/ASRM consensus criteria with PCOS women meeting two of the following three criteria: (1) oligomenorrhea or anovulation, (2) clinical and/or biochemical signs of hyperandrogenism and (3) polycystic ovaries. ${ }^{16}$ The definitions of Laven et al were used for oligomenorrhea (bleeding intervals between 35 days and 6 months) or amenorrhea (bleeding interval $>6$ months $).{ }^{17}$ Anovulation was defined as serum progesterone $<10 \mathrm{nmol} / 1$, or in the patients with normal menses, at least two consecutive low levels of serum progesterone $(<10 \mathrm{nmol} / \mathrm{l})$. Hirsutism was defined as Ferriman-Gallwey (F-G) score $\geq 6 .{ }^{18}$ Hyperandrogenemia was defined by serum total testosterone $>2 \mathrm{nmol} / \mathrm{l}$, which was based on examination of 56 nonselected women presenting for routine controls who were not hirsute, had regular cycles and had received no hormonal therapy. ${ }^{19}$ Transvaginal ultrasonography was used for the diagnosis of polycystic ovaries. The ovaries were viewed as polycystic when observed as having increased ovarian size and/or at least 12 follicular cysts measuring 2-9 mm. ${ }^{20}$ PCOS patients and controls were examined during the early follicular phase, while those with amenorrhea were evaluated after confirmation of low estrogen and progesterone concentration. None of the participants had received any oral contraceptives, glucocorticoids, antiandrogens, ovulation-inducing agents, antidiabetic and antiobesity drugs or other hormonal drugs for at least three months before the study. Participants with fasting venous glucose $\geq 6 \mathrm{mmol} / \mathrm{l}$, with pregnancy, hypothyroidism, non-classical 21-hydroxylase deficiency, hyperprolactinemia, Cushing's disease and androgen-secreting tumors were excluded from the study.

After hormonal and clinical evaluation, women with PCOS were prescribed therapies with COC containing $30 \mu \mathrm{g}$ ethinylestradiol plus $3 \mathrm{mg}$ drospirenone (Yasmin, Bayer-Schering Pharma, Leverkusen, Germany). All women with prescribed therapy for PCOS underwent the same clinical, hormonal and metabolic evaluations at baseline and after 12 months study treatment.

\section{Biochemical and hormonal measurements}

Blood samples were drawn at 08:00 h, subsequent to an overnight fast, and stored at $-20^{\circ} \mathrm{C}$ until use for hormonal measurements. Total testosterone (nmol/1), sex hormone-binding globulin (SHBG, $\mathrm{nmol} / \mathrm{l}$ ), dehydroepiandrosterone sulfate (DHEAS, $\mathrm{nmol} / \mathrm{l})$ and cortisol (nmol/1) concentrations in the serum were determined by radioimmunoassay using the following kits obtained from CIS bio international, Gif-Sur-Yvette Cedex, France: TESTO-CT2, SHBG-RIACT, DHEAS-CT and CORT-CT2, respectively. The intra- and interassay coefficients of variation were, respectively: 4.5 and $5.1 \%$ for testosterone, 3.9 and $4.7 \%$ for SHBG, 3.5 and $4 \%$ for DHEAS and 3.8 and $4.3 \%$ for cortisol. Free androgen index (FAI) was calculated from total testosterone and SHBG using the formula [(testosterone/SHBG) $\times 100] .{ }^{21}$ FAI $>8$ was considered confirmative for hyperandrogenemia.

Plasma glucose $(\mathrm{mmol} / \mathrm{l})$ was determined by the glucose oxidase method (Beckman Glucose Autoanalyser, Fullerton, USA). Serum insulin (mU/l) levels were determined by radioimmunoassay (RIA INSULIN (PEG), INEP, Belgrade, Serbia). The intra- and interassay coefficients of variation were $2.5 \%$ and $7.7 \%$, respectively. Insulin sensitivity was calculated by the homeostasis model assessment (HOMA). HOMA was calculated using the formula [fasting insulin $(\mathrm{mU} / \mathrm{l}) \mathrm{x}$ fasting glucose $(\mathrm{mmol} / \mathrm{l})] / 22.5 .^{22}$ 
Serum uric acid was determined by the colorimetric method (Randox, UK).

\section{Dexamethasone suppression test}

To assess the sensitivity of the HPA axis, an overnight dexamethasone suppression test (DST) was performed with $0.5 \mathrm{mg}$ of dexamethasone orally given at 23:00 h the preceding night. Blood samples for determination of cortisol were obtained at $08: 00 \mathrm{~h}$ the following day. Percent of cortisol suppression was calculated as [(pre-dexamethasone cortisol - post-dexamethasone cortisol)/pre-dexamethasone cortisol] $\times 100$.

\section{Isolation of peripheral blood mononuclear cells}

Peripheral blood mononuclear cells (PBMC) were prepared within one hour from blood drawing by centrifugation of blood samples through Ficoll-Paque PLUS (Amersham, UK). The cells were extensively washed and resuspended in RPMI-1640 (Gibco, UK) medium supplemented with $10 \%$ fetal calf serum (Gibco, UK) to a final density of $5 \times 10^{6}$ cells $/ \mathrm{ml}$. Cell viability was assessed by Trypan Blue exclusion and was always higher than $95 \%$. The cells were used immediately for hormone binding assay or were frozen in liquid nitrogen for other purposes.

\section{Cellular protein extraction and Western blot analysis}

PBMCs were resuspended in ice-cold TEDG buffer (10 mM Tris, $1 \mathrm{mM}$ EDTA, $2.5 \mathrm{mM}$ DTT, $10 \%$ glycerol, $0.1 \mathrm{mmol} / 1 \mathrm{PMSF}, \mathrm{pH} 7.4$ ), sonicated $(3 \times 5$ seconds, $1 \mathrm{~A}, 50 / 60 \mathrm{~Hz})$ and centrifuged $\left(14000 \mathrm{~g}, 20 \mathrm{~min}, 4^{\circ} \mathrm{C}\right)$. Protein concentration in the supernatants, referred to as whole cell extracts, was determined according to Spector ${ }^{23}$ using BSA as a reference. Aliquots containing $50 \mu \mathrm{g}$ of protein were boiled in equal volumes of $2 x$ Laemmli's sample buffer and subjected to electrophoresis $(120 \mathrm{~V}$, $4{ }^{\circ} \mathrm{C}$ ) through $7.5 \%$ SDS-polyacrylamide gels along with molecular mass references (10-170 kDa, Fermentas, Lithuania). A duplicate calibrator sample serving as internal control was applied at both ends of each gel. Western transfer of proteins from gels to PVDF membranes (Hybond-P, Amersham, UK) was carried out overnight at $135 \mathrm{~mA}$ and $4{ }^{\circ} \mathrm{C}$ in

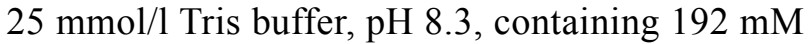
glycine and 20\% (v/v) methanol. Total GR (tGR) was detected by PA1-511A antibody (Affinity BioReagents, USA; 1:1000) and its phosphoisoform pGR-S211 was detected by ab55189 (Abcam,
1:500). Mouse monoclonal anti- $\beta$-actin antibody AC-15 (Sigma-Aldrich; 1:10000) was used as an equal loading control. Secondary antibodies were alkaline phosphatase-conjugates (Amersham Pharmacia Biotech, UK; 1:20000). The immunoreactive proteins were visualized by an enhanced chemifluorescent method (ECF; Amersham Pharmacia Biotech, UK) and the bands were analyzed by ImageQuant software (GE Healthcare, USA). Comparisons between multiple immunoblots were done by normalizing the intensity of each band to the intensity of the nearest calibrator band on the same blot and to the intensity of $\beta$-actin band in the same lane.

\section{Hormone binding assay}

Cell suspensions $\left(1 \times 10^{6}\right.$ cells $)$ were incubated $\left(120 \mathrm{~min}, 37^{\circ} \mathrm{C}\right)$ with $\left[{ }^{3} \mathrm{H}\right]$ dexamethasone (Amersham, UK; specific activity $40 \mathrm{Ci} / \mathrm{mmol}$ ) at five different concentrations ranging from 7.5-120 nmol/1. Triplicate incubations were performed in the absence and in the presence of 100-fold molar excess of unlabeled dexamethasone (Sigma-Aldrich, Germany) to determine total and nonspecific binding, respectively, and to calculate specific binding from their difference. The maximal number of receptor sites per cell $\left(\mathrm{B}_{\max }\right)$ and equilibrium dissociation constant $\left(\mathrm{K}_{\mathrm{D}}\right)$ were calculated by computer-assisted nonlinear regression. Hormone-binding potency of the receptor was calculated as $B_{\max } / K_{D}$ ratio.

\section{Statistical analysis}

The characteristics of distribution were tested with the Shapiro-Wilk test. Comparisons between groups were made by the nonparametric Mann-Whitney $U$ test. The two-related samples Wilcoxon signed rank test was used to compare changes in after-therapy values from baseline. Statistical analyses were performed with SPSS software (version 10.0, SPSS INC., Chicago, IL, USA). Results were considered statistically significant at $\mathrm{p}<0.05$.

\section{RESULTS}

\section{Anthropometrical measures, biochemical, basal hormonal characteristics and DST of women with PCOS before and after the therapy and controls}

All anthropometrical, biochemical and hormonal 
parameters of controls and PCOS patients, before and after the therapy, are presented in Table 1. There were no differences in anthropometric parameters, i.e. BMI, waist circumference and waist-to-hip ratio, between women with PCOS and healthy controls, as well as between women with PCOS, before and after the treatment.

At baseline, there were no statistically significant differences in biochemical and hormonal parameters between the PCOS group and controls in: triglycerides, total cholesterol, HDL, LDL, glucose, uric acid, insulin, HOMA index and morning cortisol. As expected, total testosterone, FAI and DHEAS were significantly higher in the PCOS than in the control group $(\mathrm{p}<0.0001$ for testosterone and FAI and $p=0.003$ for DHEAS), while SHBG was significantly lower $(\mathrm{p}=0.02)$. After the DST $(0.5 \mathrm{mg})$, PCOS women suppressed cortisol more than controls $(\mathrm{p}=0.03)($ Table 1$)$.
In the PCOS group, after the 12 months therapy with COC, levels of triglycerides $(\mathrm{p}<0.001)$, total cholesterol ( $p=0.003), \operatorname{HDL}(\mathrm{p}=0.001)$, SHBG $(\mathrm{p}=0.008)$ and cortisol $(\mathrm{p}=0.02)$ significantly increased in comparison to baseline measurements, while testosterone $(p=0.005)$, DHEAS $(p=0.02)$ and FAI $(p=0.008)$ significantly decreased (Table 1). After the 12 months of COC therapy, basal cortisol and cortisol after DST increased ( $p=0.02$ and $p=0.005$, respectively), while percentage of cortisol suppression after the DST (0.5 mg of dexamethasone) significantly decreased $(\mathrm{p}=0.003)$ (Table 1).

\section{Western blot analyses of total GR and pGR-Ser211 in PBMCs}

Relative intracellular concentrations of tGR protein was significantly elevated in women with PCOS compared to the healthy controls $(\mathrm{p}<0.05)$, while the level of pGR-Ser211 and pGR-Ser211/tGR ratio did not differ between these groups (Figure 1). After

Table 1. Anthropometrical measures, concentrations of hormones at baseline $(\mathrm{O} \mathrm{m})$ and after the 12 months $(12 \mathrm{~m})$ therapy and parameters of HPA axis activity in PCOS women and controls

\begin{tabular}{|c|c|c|c|c|c|}
\hline & $\begin{array}{c}\text { Controls } \\
(n=20)\end{array}$ & $\begin{array}{c}\text { PCOS } \\
\text { pre-therapy }(0 \mathrm{~m}) \\
(\mathrm{n}=12)\end{array}$ & $\begin{array}{c}\text { p PCOS } \\
\text { pre-therapy vs. } \\
\text { Controls }\end{array}$ & $\begin{array}{c}\text { PCOS post-therapy } \\
(12 \mathrm{~m}) \\
(\mathrm{n}=12)\end{array}$ & $\begin{array}{l}\text { p PCOS post- } \\
\text { therapy vs. PCOS } \\
\text { pre-therapy }\end{array}$ \\
\hline $\mathrm{BMI}\left(\mathrm{kg} / \mathrm{m}^{2}\right)$ & $23.50 \pm 2.25$ & $22.05 \pm 3.97$ & 0.82 & $20.98 \pm 2.20$ & 0.46 \\
\hline $\mathrm{WC}(\mathrm{cm})$ & $84.15 \pm 14.60$ & $78.17 \pm 11.47$ & 0.18 & $74.33 \pm 5.17$ & 0.62 \\
\hline Waist/Hip ratio & $0.82 \pm 0.07$ & $0.81 \pm 0.05$ & 0.95 & $0.79 \pm 0.03$ & 0.67 \\
\hline Testosterone (nmol/l) & $1.57 \pm 0.71$ & $3.30 \pm 1.34$ & $<0.0001$ & $2.33 \pm 0.72$ & 0.005 \\
\hline SHBG (nmol/l) & $56.15 \pm 26.54$ & $36.56 \pm 16$ & 0.02 & $119.41 \pm 73$ & 0.008 \\
\hline FAI & $3.41 \pm 2.01$ & $9.75 \pm 3.09$ & $<0.0001$ & $2.88 \pm 1.88$ & 0.008 \\
\hline DHEAS (nmol/l) & $4.70 \pm 1.89$ & $10.06 \pm 5.24$ & 0.003 & $6.86 \pm 3.80$ & 0.02 \\
\hline Triglycerides (mmol/l) & $1.00 \pm 0.85$ & $0.88 \pm 0.35$ & 0.83 & $1.47 \pm 0.50$ & 0.001 \\
\hline Cholesterol (mmol/l) & $5.04 \pm 1.13$ & $5.11 \pm 0.87$ & 0.79 & $5.95 \pm 1.10$ & 0.003 \\
\hline $\mathrm{HDL}(\mathrm{mmol} / \mathrm{l})$ & $1.39 \pm 0.28$ & $1.38 \pm 0.27$ & 0.80 & $1.61 \pm 0.28$ & 0.001 \\
\hline $\mathrm{LDL}(\mathrm{mmol} / \mathrm{l})$ & $3.19 \pm 1.08$ & $3.33 \pm 0.66$ & 0.53 & $3.67 \pm 1$ & 0.10 \\
\hline Glucose (mmol/l) & $4.58 \pm 0.45$ & $4.29 \pm 0.29$ & 0.08 & $4.45 \pm 0.27$ & 0.14 \\
\hline Insulin (mU/l) & $15.29 \pm 6.91$ & $15.53 \pm 10.24$ & 0.70 & $21.46 \pm 10.33$ & 0.09 \\
\hline HOMA & $3.12 \pm 1.58$ & $2.89 \pm 1.68$ & 0.52 & $4.25 \pm 2.07$ & 0.06 \\
\hline Uric acid (nmol/l) & $240.79 \pm 48.80$ & $235.14 \pm 51.64$ & 0.70 & $202.45 \pm 38.39$ & 0.11 \\
\hline Cortisol (nmol/l) & $409.27 \pm 141.77$ & $537.38 \pm 216.10$ & 0.12 & $791.00 \pm 267.57$ & 0.02 \\
\hline Cortisol after DST (nmol/l) & $43.74 \pm 39.06$ & $29.12 \pm 26.38$ & 0.41 & $100.78 \pm 68.05$ & 0.005 \\
\hline Suppression of cortisol at DST ( $\%)$ & $88.11 \pm 11.91$ & $94.71 \pm 2.71$ & 0.03 & $87.28 \pm 8.06$ & 0.003 \\
\hline
\end{tabular}

Values are means \pm SD. BMI: body mass index, WC: waist circumference, SHBG: sex hormone-binding globulin, FAI: free androgen index, DHEAS: dehydroepiandrosterone sulfate, HOMA: homeostasis model assessment, DST: dexamethasone suppression test. 
the EE-DRSP combination therapy for women with PCOS, neither relative protein concentrations of tGR and pGR-Ser211 nor pGR-Ser211/tGR ratio statistically differed before and after the therapy with COC (Figure 1).

\section{Hormone-binding properties of the $G R$}

Statistically significant differences in $\mathrm{K}_{\mathrm{D}}, \mathrm{B}_{\max }$ and GR binding potency $\left(B_{\max } / K_{D}\right.$ ratio), as indicators of
GR function, were not observed in women with PCOS and controls as well as between women with PCOS before and after the therapy with COC (Table 2).

\section{DISCUSSION}

In the present study, we demonstrated that 12 months of therapy with EE-DRSP in women with PCOS led to increased serum cortisol concentra- a)

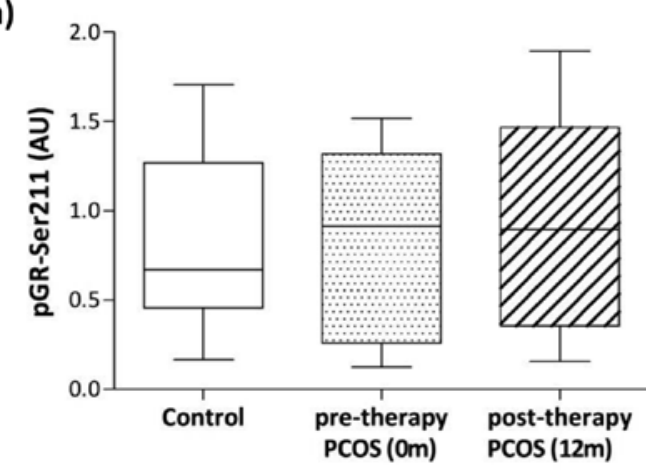

c)

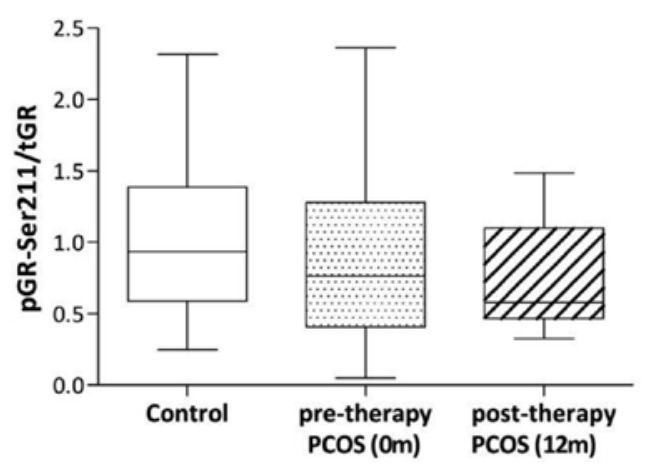

b)

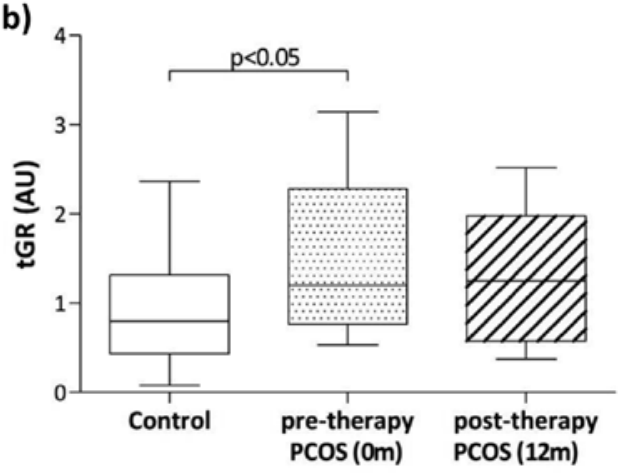

d)

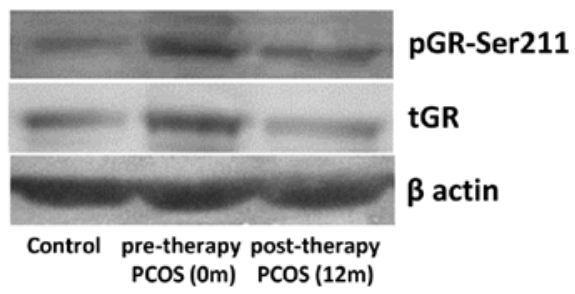

Figure 1. Protein levels of pGR-Ser211 and total GR (tGR) and their ratio (pGR-Ser211/tGR) in the whole cell extracts of PBMCs from patients with PCOS, pre- and post-therapy, and healthy controls. Proteins were separated by 7.5\% SDS-PAGE and after Western transfer, pGR-Ser211 (panel a), tGR (panel b) and $\beta$-actin, used as an equal load control, were detected by immunoblotting. Relative integrated optical densities of the immunospecific bands were determined by ImageQuant software and the results are expressed in arbitrary units (AU). Panel c) pGR-Ser211/tGR ratio calculated from the individual values for pGR-Ser211 and tGR protein levels. Panel d) a representative blot with pGR-Ser211, tGR and $\beta$-actin bands in the three groups of subjects. Significant between-group difference is indicated as $\mathrm{p}<0.05$ for pre-therapy PCOS group vs. control group.

Table 2. Figure 3 Glucocorticoid receptor hormone-binding parameters in PBMCs from pre- and post-therapy patients with PCOS and healthy controls

\begin{tabular}{lccccc}
\hline & $\begin{array}{c}\text { Controls } \\
(\mathbf{n}=\mathbf{2 0})\end{array}$ & $\begin{array}{c}\text { PCOS } \\
\text { pre-therapy }(\mathbf{0 m}) \\
(\mathbf{n}=\mathbf{1 2})\end{array}$ & $\begin{array}{c}\text { p PCOS } \\
\text { pre-therapy vs. } \\
\text { Controls }\end{array}$ & $\begin{array}{c}\text { PCOS } \\
\text { post-therapy (12m) } \\
(\mathbf{n}=\mathbf{1 2})\end{array}$ & $\begin{array}{c}\text { p PCOS post-therapy } \\
\text { vs. PCOS pre-therapy }\end{array}$ \\
\hline $\mathrm{K}_{\mathrm{D}}(\mathrm{nM})$ & $27.18 \pm 17.13$ & $36.62 \pm 26.50$ & 0.46 & $49.90 \pm 37.79$ & 0.21 \\
$\mathrm{~B}_{\max }\left(\mathrm{fmol} / 10^{6}\right.$ cells $)$ & $14.22 \pm 5.95$ & $11.83 \pm 5.15$ & 0.32 & $19.73 \pm 10.03$ & 0.10 \\
$\mathrm{~B}_{\max } / \mathrm{K}_{\mathrm{D}}$ & $0.66 \pm 0.38$ & $0.40 \pm 0.21$ & 0.12 & $0.61 \pm 0.29$ & 0.21 \\
\hline
\end{tabular}

$\mathrm{B}_{\max }$ : maximal number of receptor sites per cell, $\mathrm{K}_{\mathrm{D}}$ : equilibrium dissociation constant. 
tion and decreased sensitivity of the HPA axis to dexamethasone, but did not affect GR-Ser211 phosporylation status and GR functional parameters: $K_{D}$, $B_{\max }$ and $K_{D} / B_{\text {max }}$. Regarding metabolic effects of the administration of $\mathrm{COC}$, the combination of EE plus DRSP exerted changes in the lipid profile that are in line with recent data on PCOS. ${ }^{24}$ However, prolonged use of COC containing EE-DRSP did not influence levels of glucose and insulin, although an increase in HOMA index after the period of follow-up was observed but without reaching statistical significance.

At baseline, women with PCOS had higher levels of serum testosterone and DHEAS, lower SHBG levels and similar basal cortisol levels in comparison to healthy controls. As in our previous study, ${ }^{15}$ we confirmed an increased HPA axis sensitivity to dexamethasone and elevated tGR protein concentration in women with PCOS in comparison to healthy controls, while GR functional status, absolute and relative pGR-Ser211 concentration and basal cortisol level remained unaltered. It is well documented that GR facilitates the negative feedback of cortisol, while MR is necessary for maintaining HPA axis basal activity, particularly for feedback regulation of the pulsatile release of corticosteroids. ${ }^{25,26}$ According to the corticosteroid balance hypothesis, the shift of the MR/GR balance in favor of GR may lead the HPA axis to a hypersuppressive state. ${ }^{25}$ Although we did not determine MR levels in this study, it is possible that altered MR/GR balance is the reason for increased HPA axis sensitivity in our PCOS subjects, because tGR was significantly higher in the PCOS group than in controls. Furthermore, these changes were not followed by alterations in GR hormone binding capacity nor in its affinity for the hormone, which implies the possibility of GR redox regulation by increased oxidation of the receptor thiols that are located in the ligand binding domain and are essential for hormone binding. ${ }^{27}$

After 12 months of EE-DRSP therapy, women with PCOS had higher basal serum cortisol and lower serum DHEAS concentrations, and that is in line with other studies. ${ }^{28}$ The rise of cortisol levels after the EE-DRSP therapy in women with PCOS could be explained by estrogen induced synthesis of cortisol-binding globulin $(\mathrm{CBG})$ in the liver or its direct effect on upregulation of CRH mRNA expression in hypothalamus. ${ }^{29,30} \mathrm{On}$ the other hand, higher cortisol levels after the COC therapy could also be explained by a direct effect of DRSP that binds to MR as an antagonist with high affinity, ${ }^{31}$ as was demonstrated in previous studies. ${ }^{32,33}$ We also showed that 12 months of therapy with EE-DRSP in women with PCOS reduced HPA axis sensitivity after DST in comparison to the baseline. High CBG levels should produce the same augmentation of measured cortisol irrespectively of whether it is basal or cortisol after the DST. Bearing in mind that the DST test was started on the same day after the basal measurements and that CBG levels remain constant during 24 hours and drop substantially only 5 days after the last COC intake, ${ }^{29}$ we discard fluctuating levels of CBG as the reason for decreased sensitivity of the HPA axis in PCOS after the COC treatment.

It could be assumed that decreased HPA axis sensitivity after EE-DRSP therapy is related to lower bioavailability of physiologically active, free cortisol levels that are the consequence of $\mathrm{EE}$ induced rise of CBG. According to the free hormone hypothesis, although changes in circulating CBG levels have a significant impact on total serum cortisol levels, it is believed that free serum cortisol levels remain unaffected. ${ }^{34}$ In the presence of an intact HPA axis, feedback regulation of the cortisol production rate should compensate for estrogen effects on CBG, especially if we consider the long time (12 months) of COC use which could be enough for HPA axis adjustments. Also, we did not confirm any change in tGR concentrations or change in GR functional parameters, $B_{\max }, K_{D}$ and their ratio, which could be expected if a rise in $\mathrm{CBG}$ levels were the main reason for decreased HPA axis sensitivity.

Bearing in mind that both EE and DRSP may influence HPA axis activity, we further evaluated GR signaling and analyzed the level of GR-Ser211 phosphorylation, that correlates with GR transcriptional activity. ${ }^{30,35}$ However, there were no significant differences in tGR protein level, in phosphorylated GR-Ser211 or in their ratio before and after the EE-DRSP therapy. Accordingly, our results imply that change in HPA axis sensitivity in women with PCOS could be mediated by other postranslational 
modifications of GR and not only by phosphorylation at Ser211. Candidate posttranslational modification could be phosphorylation at Ser203 by cyclin-dependent kinase 5 that suppresses the transcriptional activity of the receptor. ${ }^{12}$

Another explanation for reduced HPA axis sensitivity to DST after 12 months of EE-DRSP therapy in women with PCOS is antagonistic action of DRSP on MR. At the hippocampal level, MR loses mineralocorticoid selectivity and binds glucocorticoids with an affinity tenfold higher than GR, while dexamethasone suppresses the HPA axis and leaves the brain depleted of naturally occurring cortisol. ${ }^{25,36}$ Under those conditions, remaining low concentrations of cortisol occupy only brain MR and not GR. ${ }^{37}$ In this situation, MR occupation by MR antagonists has a stimulatory effect on HPA activity and antagonizes the inhibitory effects of dexamethasone and/or directly activates the adrenal cortex function..$^{33,35,38}$

Related to the influence of COC on the observed metabolic outcomes in our group of women with PCOS, a possible explanation for the obtained results - this being at the same time a limitation of the study - is the relatively small examined group of subjects and study conducted on non-obese PCOS women. However, the sample size and the design of the study were similar to some previous studies on the cardiometabolic risk of the EE-DRSP use in PCOS. ${ }^{24,39}$ Further studies on larger numbers of subjects and on obese women with PCOS are needed for the clarification of the cardiometabolic effects of COC in this specific subpopulation of women.

In conclusion, we suggest that prolonged EE-DRSP combined therapy in woman with PCOS shifts the set point for glucocorticoid feedback inhibition to higher cortisol levels. Within our group of women with PCOS, treatment with EE-DRSP decreased serum androgens in the presence of decreased sensitivity of the HPA axis and with no changes in GR expression and function.

\section{FUNDING}

This work was supported by the Ministry of Education, Science and Technological Development of the Republic of Serbia, Grant III41009.

\section{CONFLICT OF INTEREST}

None.

\section{REFERENCES}

1. Azziz R, Woods KS, Reyna R, Key TJ, Knochenhauer ES, Yildiz BO, 2004 The prevalence and features of the polycystic ovary syndrome in an unselected population. J Clin Endocrinol Metab 89: 2745-2749.

2. Azziz R, Carmina E, Dewailly D, et al, 2009 The Androgen Excess and PCOS Society criteria for the polycystic ovary syndrome: the complete task force report. Fertil Steril 91: 456-488.

3. Diamanti-Kandarakis E, Papailiou J, Palimeri S, 2006 Hyperandrogenemia: pathophysiology and its role in ovulatory dysfunction in PCOS. Pediatr Endocrinol Rev 3: Suppl 1: 198-204.

4. Diamanti-Kandarakis E, 2008 Polycystic ovarian syndrome: pathophysiology, molecular aspects and clinical implications. Expert Rev Mol Med 10: e3.

5. Kumar A, Woods KS, Bartolucci AA, Azziz R, 2005 Prevalence of adrenal androgen excess in patients with the polycystic ovary syndrome (PCOS). Clin Endocrinol (Oxf) 62: 644-649.

6. Vassiliadi DA, Barber TM, Hughes BA, et al, 2009 Increased 5 alpha-reductase activity and adrenocortical drive in women with polycystic ovary syndrome. J Clin Endocrinol Metab 94: 3558-3566.

7. Yildiz BO, Azziz R, 2007 The adrenal and polycystic ovary syndrome. Rev Endocr Metab Disord 8: 331-342.

8. Ratka A, Sutanto W, Bloemers M, de Kloet ER, 1989 On the role of brain mineralocorticoid (type I) and glucocorticoid (type II) receptors in neuroendocrine regulation. Neuroendocrinology 50: 117-123.

9. Nicolaides NC, Galata Z, Kino T, Chrousos GP, Charmandari E, 2010 The human glucocorticoid receptor: molecular basis of biologic function. Steroids 75: 1-12.

10. Gross KL, Lu NZ, Cidlowski JA, 2009 Molecular mechanisms regulating glucocorticoid sensitivity and resistance. Mol Cell Endocrinol 300: 7-16.

11. Ismaili N, Garabedian MJ, 2004 Modulation of glucocorticoid receptor function via phosphorylation. Ann N Y Acad Sci 1024: 86-101.

12. Kino T, Ichijo T, Amin ND, et al, 2007 Cyclin-dependent kinase 5 differentially regulates the transcriptional activity of the glucocorticoid receptor through phosphorylation: clinical implications for the nervous system response to glucocorticoids and stress. Mol Endocrinol 21: 1552-1568.

13. Chen W, Dang T, Blind RD, et al, 2008 Glucocorticoid receptor phosphorylation differentially affects target gene expression. Mol Endocrinol 22: 1754-1766.

14. Mathur R, Levin O, Azziz R, 2008 Use of ethinylestradiol/drospirenone combination in patients with the 
polycystic ovary syndrome. Ther Clin Risk Manag 4: 487-492.

15. Vojnović Milutinović D, Macut D, Božić I, Nestorov J, Damjanović S, Matić G, 2011 Hypothalamic-pituitaryadrenocortical axis hypersensitivity and glucocorticoid receptor expression and function in women with polycystic ovary syndrome. Exp Clin Endocrinol Diabetes 119: 636-643.

16. Rotterdam ESHRE/ASRM-Sponsored PCOS consensus workshop group. Revised 2003 consensus on diagnostic criteria and long-term health risks related to polycystic ovary syndrome (PCOS). 2004 Fertil Steril 81: 19-25.

17. Laven JS, Imani B, Eijkemans MJ, Fauser BC, 2002 New approach to polycystic ovary syndrome and other forms of anovulatory infertility. Obstet Gynecol Surv 57: 755-767.

18. Ferriman D, Gallwey JD, 1961 Clinical assessment of body hair growth in women. J Clin Endocrinol Metab 21: 1440-1447.

19. Macut D, Damjanović S, Panidis D, et al, 2006 Oxidised low-density lipoprotein concentration - early marker of an altered lipid metabolism in young women with PCOS. Eur J Endocrinol 155: 131-136.

20. Balen A, Rajkowha M, 2003 Polycystic ovary syndrome-a systemic disorder? Best Pract Res Clin Obstet Gynaecol 17: 263-274.

21. Mathur RS, Moody LO, Landgrebe S, Williamson HO, 1981 Plasma androgens and sex hormone-binding globulin in the evaluation of hirsute females. Fertil Steril 35: 29-35.

22. Matthews DR, Hosker JP, Rudenski AS, Naylor BA, Treacher DF, Turner RC, 1985 Homeostasis model assessment: insulin resistance and beta-cell function from fasting plasma glucose and insulin concentrations in man. Diabetologia 28: 412-419.

23. Spector T, 1978 Refinement of the coomassie blue method of protein quantitation. A simple and linear spectrophotometric assay for less than or equal to 0.5 to 50 microgram of protein. Anal Biochem 86: 142-146.

24. Cinar N, Harmanci A, Bayraktar M, Yildiz BO, 2013 Ethinyl estradiol-drospirenone vs ethinyl estradioldrospirenone plus metformin in the treatment of lean women with polycystic ovary syndrome. Clin Endocrinol (Oxf) 78: 379-384.

25. De Kloet ER, Vreugdenhil E, Oitzl MS, Joëls M, 1998 Brain corticosteroid receptor balance in health and disease. Endocr Rev 19: 269-301.

26. DeRijk RH, de Kloet ER, Zitman FG, van Leeuwen N, 2010 Mineralocorticoid receptor gene variants as determinants of HPA axis regulation and behavior. Endocr Dev 20: 137-148.

27. Simons SS Jr, Pratt WB, 1995 Glucocorticoid receptor thiols and steroid-binding activity. Methods Enzymol 251: 406-422.

28. Guido M, Romualdi D, Giuliani M, et al, 2004 Drospirenone for the treatment of hirsute women with polycystic ovary syndrome: a clinical, endocrinological, metabolic pilot study. J Clin Endocrinol Metab 89: 2817-2823.

29. Westhoff CL, Petrie KA, Cremers S, 2013 Using changes in binding globulins to assess oral contraceptive compliance. Contraception 87: 176-181.

30. Weiser MJ, Handa RJ, 2009 Estrogen impairs glucocorticoid dependent negative feedback on the hypothalamicpituitary-adrenal axis via estrogen receptor alpha within the hypothalamus. Neuroscience 159: 883-895.

31. Elger W, Beier S, Pollow K, Garfield R, Shi SQ, Hillisch A, 2003 Conception and pharmacodynamic profile of drospirenone. Steroids 68: 891-905.

32. Arvat E, Maccagno B, Giordano R, et al, 2001 Mineralocorticoid receptor blockade by canrenoate increases both spontaneous and stimulated adrenal function in humans. J Clin Endocrinol Metab 86: 3176-3181.

33. Wellhoener P, Born J, Fehm HL, Dodt C, 2004 Elevated resting and exercise-induced cortisol levels after mineralocorticoid receptor blockade with canrenoate in healthy humans. J Clin Endocrinol Metab 89: 5048-5052.

34. Mendel CM, 1989 The free hormone hypothesis: a physiologically based mathematical model. Endocr Rev 10: 232-274.

35. Heuser I, Deuschle M, Weber B, Stalla GK, Holsboer F, 2000 Increased activity of the hypothalamus-pituitaryadrenal system after treatment with the mineralocorticoid receptor antagonist spironolactone. Psychoneuroendocrinology 25: 513-518.

36. Grossmann C, Scholz T, Rochel M, et al, 2004 Transactivation via the human glucocorticoid and mineralocorticoid receptor by therapeutically used steroids in CV-1 cells: a comparison of their glucocorticoid and mineralocorticoid properties. Eur J Endocrinol 151: 397-406.

37. van Leeuwen N, Kumsta R, Entringer S, et al, 2010 Functional mineralocorticoid receptor (MR) gene variation influences the cortisol awakening response after dexamethasone. Psychoneuroendocrinology 35: 339-349.

38. Berardelli R, Karamouzis I, Marinazzo E, et al, 2010 Effect of acute and prolonged mineralocorticoid receptor blockade on spontaneous and stimulated hypothalamicpituitary-adrenal axis in humans. Eur J Endocrinol 162: 1067-1074.

39. Mancini F, Cianciosi A, Persico N, Facchinetti F, Busacchi P, Battaglia C, 2010 Drospirenone and cardiovascular risk in lean and obese polycystic ovary syndrome patients: a pilot study. Am J Obstet Gynecol 202: 169 e1-8. 